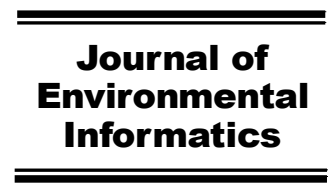

www.iseis.org/jei

\title{
Information Provision in Environmental Policy Design
}

\author{
V. Danilina ${ }^{1 *}$ and A. Grigoriev ${ }^{2}$ \\ ${ }^{1}$ Aix-Marseille Univ., CNRS, EHESS, Centrale Marseille, AMSE 5-9 Boulevard Bourdet, CS 5049813205 Marseille Cedex 1, France \\ ${ }^{2}$ Maastricht University School of Business and Economics, QE/SBE, P.O. Box 616, 6200 MD Maastricht, \\ The Netherlands
}

Received 10 January 2018; revised 9 July 2018; accepted 18 December 2018; published online 20 April 2019

\begin{abstract}
Information provision is a relatively recent but steadily growing environmental policy tool. Its emergency and topicality are due to the current escalation of ecological threats. Meanwhile, its high complexity and flexibility require a comprehensi ve approach to its design, which has to be tailored for specific characteristics of production process, market structure, and regulatory goals. This work proposes such an approach and builds a framework based on a three-level mathematical program extending well-known two-level Stackelberg game by introducing one more economic agent and one extra level of this sequential game. This study provides simple and very intuitive algorithms to compute optimal multi-tier information provision policies, both mandatory and voluntary. The paper urges for the wide implementation of such efficient environmental policy design tools.
\end{abstract}

Keywords: environmental policy, information provision, eco-certification, eco-labelling, multi-level mathematical programming, stackelberg game, exact algorithms

\section{Introduction}

Present escalation of ecological threats requires public sector to introduce comprehensive regulatory instruments. Recent research on development of environmental policies provides already quite a wide range of regulatory tools to address ecologycal problems. These tools differ in their predominantly targeted areas, economic agents, compulsion, degree of distortion and incentivizing/restrictive nature (Albrizio et al., 2014). The variety of the instruments allows adjusting the regulations to account for specific negative environmental effects. At the same time, growing ecological concerns in the society provide a fertile background for the development of information provision as a relatively new and very promising environmental policy instrument. This approach refers to any type of indicators alerting for ecological footprint of a particular good and awaking green preferences of market agents.

Information provision instruments can be ranked by their informative degree from relatively simple binary indicators which distinguish clean and dirty types of goods to more sophisticated multi-tier ones (Fischer and Lyon, 2017), which allocate products to a range of categories according to their environmental footprint. The latter approach corresponds, for example, to such mandatory policy tools as EU Energy Label dis-

${ }^{*}$ Corresponding author. Tel.: +33 (0)781551921; fax: +33 (0)413552560. E-mail address: vera.danilina @univ-amu.fr (V. Danilina).

ISSN: $1726-2135$ print/1684-8799 online

(C) 2019 ISEIS All rights reserved. doi:10.3808/jei.201900410 playing energy efficiency of the appliance (Council of the European Communities, 1992), US Monterey Bay Aquarium Seafood Watch programme indicating how far the particular kind of fish is from depletion, Dutch Beter Leven and German Für Mehr Tierschutz labelling ecological quality of meat.

Besides its positive ecological impact and efficient technological implementation, an information provision programmme is also expected to be attractive and transparent for consumers. To reach this goal, an information provision programme has to meet at least three following requirements. First, the regulatory policy should support, or even enforce, consumer's higher willing-ness-to-pay for environmentally friendly varieties. Second, to ensure the efficiency of the programme, its signals should be intuitive and clear. They should account for consumers' awareness of ecological threats and refer to the footprints of production process. Third, consumers' appreciation of the information provision depends on stringency of the established ecological criteria. If the stringency is low and relatively large share of existing technologies is labelled as green, the consumers' response is less appealing and the regulatory policy can be perceived as vague and non-informative. Thus, the program should aim for high standards and sharply differentiated technologies. Notice, however, if the policy implies too tough standards and there is only a tiny share of products satisfying those standards, the programme, though highly appreciated by consumers, will be of a very limited representation on the market.

Despite numerous implementations of multi-tier information provision instruments all over the world (Minkov et al., 2015), efficiency of their design remains rather unexplored. A notable exception is a research by Fischer and Lyon (2017) where they 
propose a theory of multi-tier eco-labels allowing for two types of stakeholders, NGO and industry trade union, and consumer eco-preferences heterogeneity. Within a vertical product differentiation framework they show that a range of outcomes is conditional on the entry/exit firms' dynamics and the unique equilibrium implies a choice of binary labels by both institutions.

The present research aims at filling the gap in the literature by presenting a mathematical model for the information provision regulation maximising the social welfare. It proposes a framework based on the three-level programming aiming to explore welfare gains under several scenarios implying a multitier information provision programme. It studies four scenarios different in two aspects: (i) a type of decision-maker-government or/and industry association, and (ii) policy enforcement-mandatory (eco-certification) or voluntary (eco-labelling). The research starts from developing a benchmark model where government unilaterally determines the criteria of the information provision programme in order to maximise social welfare, while the industry is obliged to follow that programme. Then, the unilateral decision-making is relaxed to account for deviations when the industry may selfishly optimise its utility or voluntarily decide upon the participation in the regulatory programme. These scenarios correspond to the cases when the market is served by a multiproduct monopoly or by a set of competitive firms whose interests, nevertheless, are represented by an industry association. The research provides insightful and very intuitive algorithmic techniques allowing the regulatory institution to develop optimal information provision programmes reflecting specific characteristics of demand and production process, consumer attitudes towards environmental problems, and market organisation.

This paper provides a set of algorithms that incorporate optimisation problems in order to design an efficient multi-level information provision environmental policy. Algorithmic approach as well as optimisation methods in programming aiming to tackle upon environmental issues have been already introduced in the literature: for example, Tegos and Onkov (2009) develop an algorithm for categorising fish species at risk, and Yeomans (2008) applies the simulation-optimisation methods to the ecological policy under uncertainty. Meanwhile, to the best of our knowledge, the current research is the first attempt to embed multilevel mathematical programming in environmental policy design for finding an optimal information provision regulation for real-life cases in reasonable time. Moreover, the model incurporates both, mandatory and voluntary, instruments and extends the focus to the multi-tier information provision instruments considering heterogeneity in eco-preferences across consumers. This research can be of interest for both the academic community and policy makers. For the academic community, this work provides a very generic methodological approach that is easily adjustable and replicable in many other economic settings. For practitioners, the paper can be regarded as a cookbook. The methods described in the article are simple, intuitive and clear allowing policy makers to directly apply the methods in order to determine the optimal certification/labelling design and pricing policies.

The rest of the paper is organised as follows. Section 2 overviews the environmental public policy regulation with par- ticular focus on information provision instruments. Section 3 presents the general structure of the model. Section 4 describes the algorithms solving the model. Section 5 illustrates the algorithms on simple numerical examples. Finally, section 6 discusses the results and concludes.

\section{Information Provision as An Environmental Policy Instrument}

Environmental policy entered the global agenda in the late 1960s early 1970s in developed countries and consistently spread around the world. Traditionally, existing green regulatory instruments are grouped along with the phases of development (see, for example, Tietenberg, 1998). The first phase is related to the command-and-control, or direct regulations, based on emissions, technological standards, and certification. These instruments are traditionally highly distorting and costly to implement. During the second phase, in order to comply with these shortcomings, the market-based (or incentive-based, Goulder and Parry, 2008) approaches were introduced. Such regulatory tools as emission quotas and taxes, subsidies, tradable permits tend to be more flexible and cost-efficient. The third phase referring to the provision of information has been evolved due to three main reasons. First, due to the increasing complexity of environmental problems it becomes highly inefficient to target the problems by direct or market-based instruments. Second, due to the credence nature (Darby and Karni, 1973) of eco-friendly goods, there is a need for additional signals concerning the green quality of a particular variety of goods. This need comes from inability of consumers to disclose this information even after the purchase. Third, due to falling costs of information collection, information dissemination, and rapid growth of consumers' and producers' eco-awareness, the information provision instruments become significant, if not decisive, on the market. Carlsson et al. (2010) report a sharp increase in the green preferences of consumers over the last 15 years. As a result, the number of environmental labelling, promotional programmes, and information schemes demonstrate a fivefold increase along the period 1970 2012 (Gruère, 2013).

For the purpose of this research the information provision instruments are categorised according to their informative degree. Particularly, this allows distinguishing between binary and multi-tier approaches to information disclosure. The binary approach refers to one-category programmes while the multitier approach allows defining several categories within one classification scheme (see Table 1 for examples).

Multi-tier information provision instruments fall under the umbrella of the Type III environmental declarations (or Environmental Product Declarations (EPD)) that provide “...quantified environmental data using predetermined parameters and, where relevant, additional environmental information ..." (ISO 14025:2006). Therefore, these information provision instruments indicate the life-cycle environmental impact of a particular variety. Rules and requirements, allowing for EPDs, shape product category rules (PCR) that have been growing rapidly (Minkov et al., 2015). Ingwersen and Stevenson (2012) report over 300 PCRs developed only by government-related organisations that 
account predominantly for the well-established instruments.

\section{The Model}

The model aims to find a socially optimal information provision design in a partial equilibrium setting in a market of a single environmentally-unfriendly good. The market is operated by three types of agents: consumers, producers, and government. The good is eco-credence, i.e., consumers are not able to distinguish between clean and dirty technologies without additional information that can be provided by any type of productspecific identifiers (for example, eco-labelling or eco-certificates) that indicate the ecological footprint of a particular type of a good. For this purpose of information provision, government, as a market regulatory agent, categorises the production modes, indicated by $k \in\{0, \ldots, K\}$ into $K$ types, $K \geq 1$. Without loss of generality, the model assumes that the good obtained from the production of level $k=0$ is non-labelled, and the higher are the values of $k$, the more environmentally-friendly is the production process. It is convenient to refer to the production levels of the good also as the types of good. It is also assumed that each information provision programme has a particular stringency level $s \geq 1$. Stringency parameter $s$ is determined by a set of ecological criteria established by the government. This parameter is explicitly defined later when the role of the government in the model is discussed.

Consumers. The economy is populated by $N$ consumers. Each consumer $j \in\{1, \ldots, N\}$ chooses a type of the good to buy, if at all. If type $k \in\{0, \ldots, K\}$ is chosen, consumer $j$ identifies the demand $d_{j k} \in Z^{+}$for this type. Each consumer has different ecoconcerns implying two types of eco-heterogeneity across consumers. Consumers make purchasing decisions based, first, on the personal willingness-to-pay for a particular type of the good; and second, on their perception of the information provision programme stringency.

The first source of eco-heterogeneity that is related to the consumers' willingness-to-pay is captured by different budgets: consumer $j$ is willing to pay for $d_{j k}$ units of the good type $k$, at most $b_{j k} \geq 0$ monetary units. This assumption is based on the empirical findings that prove the existence of green preferences. For instance, Bjørner et al. (2004) report that consumers are willing to pay a $13 \sim 18 \%$ premium for the varieties certified by the Nordic Ecolabel.

The second source of eco-heterogeneity that is related to the policy design and its perception by consumers is captured by the regulation stringency parameter $s \geq 1$ and the stringencyspecific consumer myopia parameter $\mu^{s} \geq 0$, respectively. Myopia parameter $\mu^{s}$ reflects consumers' heterogeneity in their environmental policy appreciation due to their personal preferences. For example, some consumers might be eco-indifferent and assign low weights to the regulation stringency. The others can value the stringency much higher due to their high eco-concerns. Myopia is represented by a vector of consumer and policy design parameters $\mu_{j}^{s}=\left\{\mu_{j 1}^{s}, \ldots, \mu_{j K}^{s}\right\}$ in such a way that the impact of stringency to consumer preferences is relatively higher for more environmentally-friendly varieties: $\mu_{j k}^{s} \leq \mu_{j, k+1}^{s}$ for any $1 \leq k<K$. The current research treats the myopia parameter as the monetary value assigned by consumers to one unit of stringency $s$. It also assumes parameters $b$ and $\mu$ being independent.

Now, given the prices $p_{0}, p_{1}, \ldots, p_{K}$ for the types of the good, the money-metric utility of consumer $j$, considering the good of type $k$, is defined by:

$\omega_{j k}=b_{j k}-p_{k} d_{j k}+\mu_{j k}^{s} s$

If the utility is negative, i.e., $\omega_{j k}<0$, consumer $j$ does not buy the good of type $k$. If there is at least one type of the good with a positive utility for consumer $j$, the type that delivers the maximum utility is chosen. Thus, the realised utility received by consumer $j$ is $\omega_{j}<\max \left\{0 ; \max _{k} \omega_{j k}\right\}$.

This paper assumes that the government and producers have complete information about the consumers' preferences.

Producers and technology. There are $M$ available technologies in the industry each of which refers to a discrete set $\left\{c_{i}, \varphi_{i}\right\}, i \in\{1, \ldots, M\}$, where $c_{i}>0$ represents variable costs of production measured in monetary units and $\varphi_{i} \geq 0$ represents environmental footprints per unit produced. The footprints are considered as expenditures needed to neutralise the eco-damage of production. The set of technologies is assumed to be such that higher variable costs correspond to the lower footprints. The number of types of the good defined by the government cannot exceed the number of available technologies $K \leq M$.

The good can be produced with any of the $M$ technologies in unlimited quantity. The goal of the producers utilizing technology $i$ is to setup the price $p_{i}$ maximising the profit:

$\pi_{i}=\left[p_{i}-c_{i}\right] x_{i}$

where $x_{i}$ is the quantity of the good produced. Notice, in an equilibrium the production is equal to the consumption, i.e., $\forall k, \quad x_{k}=\sum_{j=1}^{N} d_{j k}$. If $\pi_{i}<0$, the producer leaves the market. The aggregate industry profit is:

$\Pi=\sum_{j=1}^{M}\left[p_{i}-c_{i}\right] x_{i}$

The model does not allow for industry eco-altruism, i.e., there are no incentives to introduce green technologies induced by any other factors but the eco-bias in consumer preferences. It is assumed that the government has complete information about the available technologies.

Government. The government is a benevolent planner who aims for social welfare maximisation that is defined by

$W=\sum_{j=1}^{N} \ln \left(\omega_{j}+1\right)+\Pi-\Phi$

where $\Phi=\left(\sum_{i=1}^{M} \varphi_{i} x_{i}\right)^{\gamma}$ represents the aggregate social preference over negative environmental impact of production and $\gamma \geq 0$ is a common amplification parameter, provided in the input. It is assumed that $W$ and $\Phi$ are measured in monetary units. Here, the consumers are risk-averse while the producers are risk-neutral 
Table 1. Examples of Information Provision Programmes

\begin{tabular}{l}
\hline Programme (Information) \\
BINARY PROGRAMMES \\
Energy Star \\
(greenhouse gas emissions) \\
Nordic Swan Ecolabel \\
(sustainable consumption) \\
MULTI-TIER PROGRAMMES \\
Für Mehr Tierschutz \\
(ecological quality of meat) \\
Beter Leven \\
(ecological quality of meat) \\
Monterey Bay Aquarium Seafood Watch \\
(overexplotation of fish stocks) \\
Agricultural Marketing Service \\
(diary products) \\
(ecological quality of diary products) \\
Global Animal Partnership \\
(welfare of farmed animals) \\
EU Energy Label \\
(energy consumption)
\end{tabular}

(Bernoulli, 1738). Therefore, the consumers' part of the social welfare is concave (logarithmic) exhibiting diminishing marginal utility while the producer part implies the marginal utility to equalise one unit of profit increase (linear).

As mentioned above, in order to reach the policy goal, the government designs a $K$-level information provision programme that can take a form of mandatory or voluntary regulation. Mandatory information provision programme, or eco-certification, implies that all technologies/producers obtain a compulsory certificate that reflects the footprint of their production process. Voluntary information provision programme, or eco-labelling, sets the criteria to obtain a certain label but producers are free to decide whether they want that label or not. It is assumed that this decision is solely based on profitability.

To determine the rules of an information provision programme, the government defines a set of footprint delimiters $D=\left\{D_{1}\right.$, $\left.\ldots, D_{K}\right\}, \quad D_{k+1} \leq D_{k}$. A footprint delimiter is a variable to be determined by the government to optimize the social welfare. A footprint delimiter is measured in monetary units. The goal of setting up the delimiters is to group/classify the technologies according to their footprints and to identify the information provision certificates or labels for those groups of technologies. As a footprint is the expenditures needed to eliminate the negative per unit environmental impact of the production process for a certain type of the good, the delimiters allow to segregate the technologies by their ecological footprint, i.e., the technologies with per-unit footprint $\varphi \in\left[D_{1}, \infty\right)$ obtain no label, and the technologies with footprint $\varphi \in\left[D_{k+1}, D_{k}\right.$ ) are obliged (ecocertification) or allowed (eco-labelling) to obtain a $k$-label; see Figure 1. In case of eco-labelling, producers are also allowed to choose the lower quality labels since they meet the corresponding environmental requirements while profit maximizing. In this case, firms can find profitable not to disclose their actual environmental quality when, for example, consumers are ecosceptical and prefer to buy brown products rather than the labelled ones.

Due to possibly higher profits generated by eco-friendly varieties, producers might also be incentivised to cheat and choose for the quality labels, which are higher than the labels allowed by the actual environmental footprints. This phenomenon is well known and is referred as greenwashing. In the present model, the greenwashing is ruled out by assuming efficient government monitoring of the programme implementation.

The choice of delimiters composition determines the stringency of the information provision programme denoted by $s \geq 1$. This parameter allows ranking the policy designs in the following way. Assume there are $m_{0} \geq 0$ technologies that do not meet the requirements of the designed policy to obtain any type of label, and there are $m_{i}$ technologies with footprint $\varphi \in\left[D_{i}-1, D_{i}\right)$ that can be marked with a label $i$. Thus, $\sum_{i=0}^{K} m_{i}=M$. Then, the stringency parameter is defined by:

$s=\sum_{j=0}^{K}\left(m_{j} / \sum_{i=j}^{K} m_{i}\right)$

Here, the lower is the share of technologies that can obtain a label, the higher is the stringency parameter.

Like in Stackelberg games (Stackelberg, 1952), the present model has a leader, namely the government, which moves first 


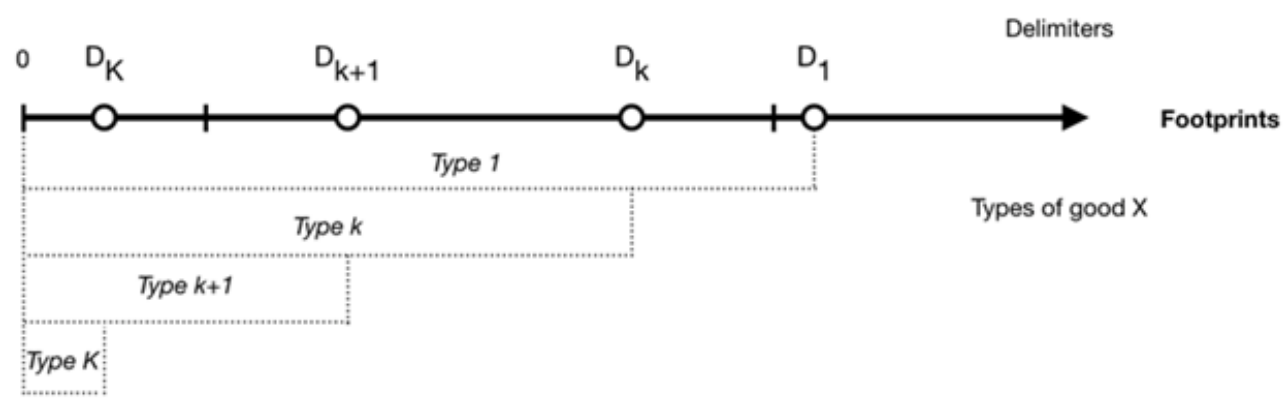

Figure 1. Regulatory delimiters and types of the good.

Notes: Delimiters and footprints are measured in monetary units. They indicate the expenditures that are needed to eliminate per unit of production negative environmental impacts.

Table 2. Policy Scenarios

\begin{tabular}{|c|c|c|c|c|}
\hline & Scenario C certification ${ }^{*}$ & Scenario L labelling ${ }^{\#}$ & Scenario CI certification ${ }^{*}$ & Scenario LI labelling ${ }^{\#}$ \\
\hline Government & $\begin{array}{l}\text { objective: social welfare (4) } \\
\text { variables: delimiters and prices }\end{array}$ & $\begin{array}{l}\text { objective: social welfare (4) } \\
\text { variables: delimiters and prices }\end{array}$ & $\begin{array}{l}\text { objective: social welfare (4) } \\
\text { variables: delimiters }\end{array}$ & $\begin{array}{l}\text { objective: social welfare (4) } \\
\text { variables: delimiters }\end{array}$ \\
\hline $\begin{array}{l}\text { Industry } \\
\text { Association/ }\end{array}$ & - & - & $\begin{array}{l}\text { objective: industry profit (3) } \\
\text { variables: prices }\end{array}$ & $\begin{array}{l}\text { objective: industry profit ( } 3) \\
\text { variables: prices }\end{array}$ \\
\hline Producers & - & choose a label & - & choose a label \\
\hline Consumers & $\begin{array}{l}\text { objective: utility (1) } \\
\text { variables: type of the good }\end{array}$ & $\begin{array}{l}\text { objective: utility (1) } \\
\text { variables: type of the good }\end{array}$ & $\begin{array}{l}\text { objective: utility (1) } \\
\text { variables: type of the good }\end{array}$ & $\begin{array}{l}\text { objective: utility (1) } \\
\text { variables: type of the good }\end{array}$ \\
\hline
\end{tabular}

* (eco-)certification implies mandatory assignment of types of the good.

\# (eco-)labelling allows firms to choose the type of the good voluntarily.

and decides upon the information provision programme (delimiters). Then, the followers, namely the producers, set the prices and decide (if allowed) whether to participate in the programme, or not. Finally, in the third level, the consumers choose the types of the good to buy in order to maximise their utility. The sequential game in this paper is an extension of the classic twolevel Stackelberg game by introducing an extra player/agent (government) acting on the third (top) level of the game.

\section{Scenarios}

The research develops four possible scenarios related to particular market settings; see Table 2 . The goal is to estimate the deviations in the social outcomes of information provision environmental regulation conditionally on the policy design and economic agents' interdependence. For each scenario, this paper presents an algorithm and illustrates the algorithm by a simple numerical example.

All scenarios imply the consumers' willingness to maximise their utility (1) by choosing the corresponding type of the good. Their choice is determined by the decisions made by the government and/or by producers that might narrow the range of types of the good available on the market.

The first scenario is considered as a benchmark where the government is the only economic agent who is taking action. The main goal of the latter is to maximise the social welfare
(4). The government unilaterally decides upon the design of the mandatory eco-certification, i.e., the delimiters, and upon the prices of the corresponding types of the good. Producers take all the parameters as given. Accordingly, they are obliged to certify their production according to its environmental quality. It is referred as Scenario $C$, where $C$ stands for "certification".

The second scenario features the same properties as the first one, in addition providing a possibility for producers to choose whether to label their production or not. They can also hide the real environmental quality by choosing a label of the lower level (but not of the higher level as far as the model does not allow to greenwash). The second scenario refers to Scenario L, where $L$ stands for "labelling".

The third scenario introduces an industry association who sets the prices for all types of the good. Here, the government chooses the delimiters that are mandatory for the producers, while the industry association decides for the prices in order to maximise the aggregate industry profit (3). This is referred as Scenario CI, where CI stands for "certification" and "industry".

Finally, the third scenario turns into the fourth one by allowing producers to voluntary decide upon joining the information provision programmes (eco-labelling). Here, producers decide whether to take the label or not, while the industry association sets the prices for each type of the good. The forth scenario is referred as Scenario $L I$, where $L I$ stands for "labelling" and "industry". 


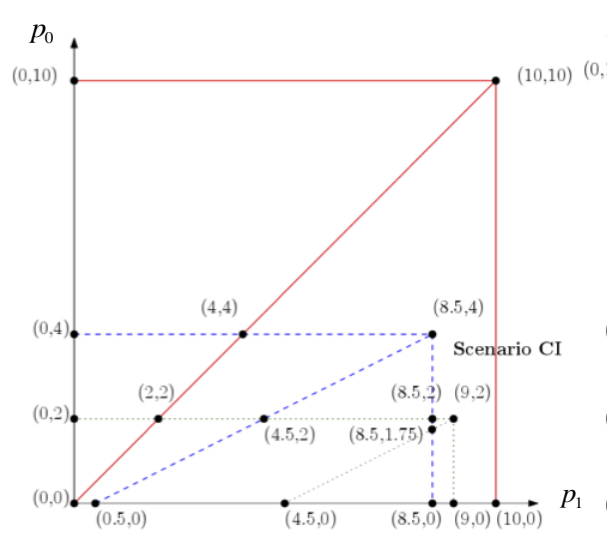

(a) Stringency $s=0.5$

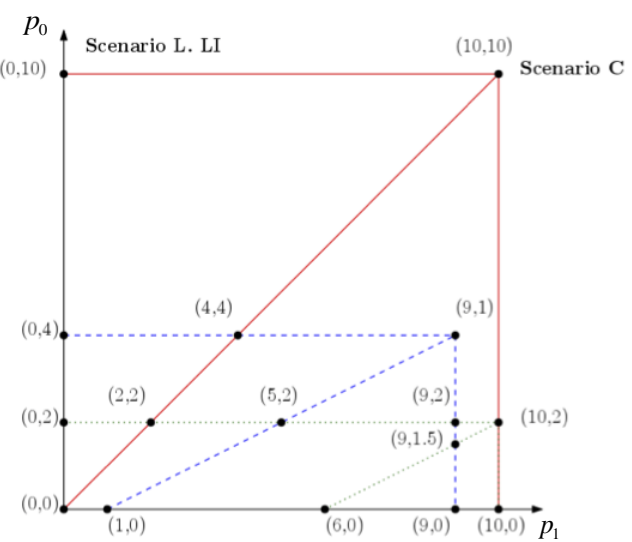

(b) Stringency $s=1$

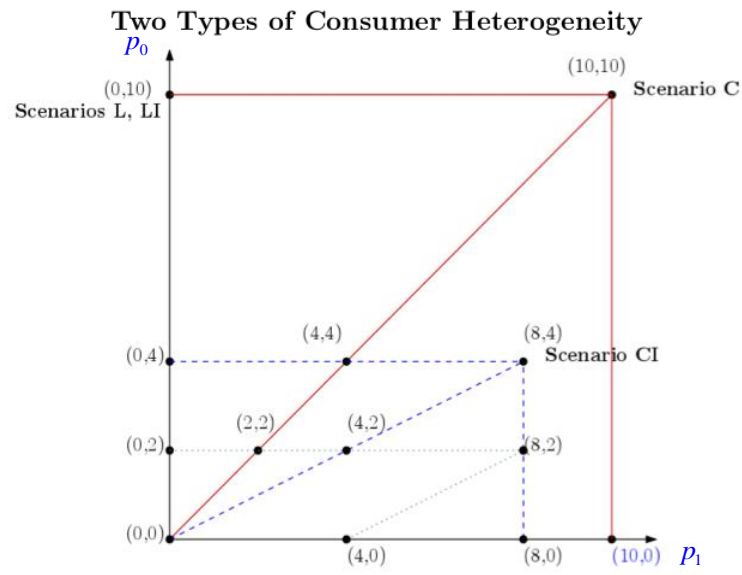

One Type of Consumer Heterogeneity

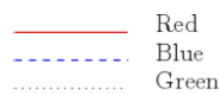

Figure 2. Price spaces conditionally on information provision stringency. Notes: Prices are measured in monetary units.

\subsection{Computing Optimal Delimiters and Prices}

Let the price space be a $(K+1)$-dimensional space defined by prices of each type of the good. Let the bounding box of consumer $j$ be a rectilinear box in the price space determined by affordable prices only, i.e., the prices allowing a positive demand: $0 \leq p_{k} \leq\left(b_{j k}+\mu_{j k}^{s} s\right) / d_{j k}$ for all $k \in\{0,1, \ldots, K\}$. Let the hyperplane $p_{k} \leq\left(b_{j k}+\mu_{j k}^{s} s\right) / d_{j k}$ be referred as a box hyperplane. Let an indifference hyperplane of consumer $j$ be a hyperplane in the price space such that consumer $j$ is indifferent between two types of the good, $k$ and $k^{\prime}, k \neq k^{\prime}: b_{j k}-p_{k} d_{j k}+\mu_{j k^{s}}^{s} s=b_{j k^{\prime}}-$ $p_{k^{\prime}} d_{j k^{\prime}}+\mu_{j k^{s}}^{s}$. Let a price vertex be a point in the price space determined by the intersection of any $K+1$ linearly independent box/indifference hyperplanes. Let a price region be a polyhedron in the price space bounded by box/indifference hyperplanes that does not contain any price vertex in the interior. Each price region is a convex hole of the price vertices.

Notice that in any price region each consumer's choice is fixed. In any optimal solution, the set of delimiters is a subset of the finite footprint set $\left\{D_{1}, \ldots, D_{K}\right\} \subset\left\{\varphi_{1}, \ldots, \varphi_{M}\right\}$. Moreover, the model rules out the cases when the government introduces delimiters in such a way that all technologies can obtain a certificate or a label, or no technology can be certificated or labelled. If there are $M$ available technologies and the government aims to develop a $K$-types information provision programme, the optimal allocation of delimiters can be found by straightforward brute-force enumeration over all choices of $K$ delimiters out of $M$ available footprints. Thus, it is required to solve at most $O\left(M^{K}\right)$ problems with given delimiters. If $K$ is a little constant, then the number of problems to solve is relatively small and even a mediocre capacity PC can tackle such a task. Therefore, the optimal solution retrieval time in all scenarios is at most $O\left(M^{K}\right)$ times the retrieval time of the optimal prices, given a delimiters allocation. The reasonable number $K$ is, indeed, at most 9 according to the Miller's Law stating that an average human can hold in the working memory $7 \pm 2$ objects (Miller, 1956), or at most 4 according (Cowan, 2000). In practice, the existing environmental information provision programmes imply from 1 to 7 levels such as Nordic Swan Ecolabel (Nordic countries, 1 level), Für Mehr Tierschutz (Germany, 2 levels), Beter Leven (the Netherlands, 3 levels), Monterey Bay Aquarium Seafood Watch (USA, 4 levels), Agricultural 
Marketing Service (USA, 5 levels), Global Animal Partnership (USA, 6 levels), EU Energy Label (7 levels). Thus, throughout the paper $K$ is fixed, i.e., it is a little constant.

Since in all four scenarios the overall governmental objective function is the mix of the logarithmic and the linear one (in prices), the first order conditions deliver a finite set of optimal roots and therefore the finite number of potentially optimal solutions. Moreover, by Karush-Kuhn-Tucker conditions, optimal solutions are necessarily the price vertices of the price regions. That allows solving the problem of finding the optimal prices, given the delimiters, by a brute force enumeration of price vertices in time $O\left(N^{K}\right)$. This implies the overall time complexity of our algorithms is at most $O\left(N^{K} M^{K}\right)$.

\subsection{Scenario $C$}

Benchmark case is related to the eco-certification when each technology acquires a mandatory certificate in accordance to the footprint. The criteria of certification and corresponding prices are unilaterally determined by the government in order to maximise the social welfare. The first scenario delivers the maximum possible welfare outcomes under the general assumptions of the model.

Algorithm. The government determines a family of optimal delimiters $D \in\left\{D_{1}, \ldots, D_{K}\right\}$ by brute-force enumeration of all $K$ elementary subsets from the footprint set of size $M$.

Given a set of delimiters $D$, a particular stringency parameter $s$ is uniquely defined as well as the set of consumer utility functions. Thus, the partition of the price space into price regions is completely and uniquely determined. For each price vertex in the price space each consumer chooses the optimal type of the good to purchase or exits the market if none of the types is affordable. This determines the aggregate industry profit and the summands of the social welfare. The procedure is repeated for each set of delimiters. The maximum obtained social welfare $W^{*}$ together with the respective set of delimiters $D^{*}$ and the price vector $p^{*}=\left(p_{0}^{*}, p_{1}^{*}, \ldots, p_{K}^{*}\right)$ represent an optimal benchmark solution; see Algorithm 1 in the supplementary material.

\subsection{Scenario $L$}

Scenario $L$ is identical to Scenario $C$ in all aspects except for the nature of the information provision programme. Now producers who acquire optimal technology are allowed to voluntarily choose whether they accept the label, or not. Furthermore, they can take the label they match to, or a lower one, or remain non-labelled.

Algorithm. As in Scenario $C$, the government determines a family of optimal delimiters. For each set $D$ there is a family of $K^{K}$ sets each of which represents producers' choice of a type for the produced variety $\kappa=\left\{\kappa_{0}, \kappa_{1}, \ldots, \kappa_{K}\right\} \in Z^{K+1}$. Given a sets of delimiters $D$ and selected types $\kappa$, a particular stringency parameter $s$ and a set of consumer wealth functions are uniquely defined. The rest of the algorithm is the same as in Scenario $C$. The procedure is repeated for each set of delimiters and producers' type choice. The maximum obtained social welfare $W^{*}$, the respective sets of delimiters $D^{*}$, the optimal producers' type choice $\kappa^{*}$, and the price vector $p^{*}=\left(p_{0}^{*}, p_{1}^{*}, \ldots, p_{K}^{*}\right)$ represent an optimal solution; see Algorithm 2 in the supplementary material.

\subsection{Scenario CI}

The third scenario introduces an industry association playing in the common interest of the producers. Therefore, the government sets criteria of eco-certification maximising the social welfare while the pricing policy is assumed to be made by the association who seeks for maximization of the aggregate industry profit.

Algorithm. As before, the government determines a family of optimal delimiters $D \in\left\{D_{1}, \ldots, D_{K}\right\} \in Z_{+}^{K}$ that allows to uniquely define the partition of the price space into price regions. For each price vertex in the price space each consumer makes the same choice as before. This determines the aggregate industry profit for each price vertex in the price space. The industry association chooses the price vertex that yields the maximum aggregate industry profit. Given the maximum aggregate industry profit, the government calculates the social welfare. The procedure is repeated for each set of delimiters. Again, the maximum obtained social welfare $W^{*}$, the maximum aggregate industry profit $\Pi^{*}$, the set of delimiters $D^{*}$, and the price vector $p^{*}=\left(p_{0}^{*}, p_{1}^{*}, \ldots, p_{K}^{*}\right)$ represent an optimal solution; see Algorithm 3 in the supplementary material.

\subsection{Scenario $L I$}

In the fourth scenario, the government and the industry association aim at the same goals as in Scenario CI but now firms are allowed to voluntarily decide whether they introduce the label as in Scenario L or not.

Algorithm. The first part of the algorithm coincides with the algorithm designed for Scenario $L$. Then, for each price vertex in the price space, the industry association calculates the aggregate industry profit. For the price vertex with the maximum aggregate industry profit, the government calculates the social welfare. The procedure is repeated for each set of delimiters $D$, producers' type choice $\kappa$. The maximum obtained social welfare $W^{*}$, the maximum aggregate industry profit $\Pi^{*}$, the set of delimiters $D^{*}$, the optimal producers' type choice $\kappa^{*}$, and the price vector $p^{*}=\left(p_{0}^{*}, p_{1}^{*}, \ldots, p_{K}^{*}\right)$ represent an optimal solution; see Algorithm 4 in the supplementary material.

\section{Numerical Example}

Each scenario developed in the previous section assumes that decision makers are fully informed about the consumers' preferences for different types of the good (budgets $b_{j k}$ and regulation stringency myopia $\mu_{j k}^{s}$ ) and production technologies (variable costs of production $c_{i}$ and ecological footprints $\varphi_{i}$ ). Recall that all the data is considered to be represented in monetary units: budgets $b_{j k}$ correspond to the monetary restrictions of consumer $j$ for the $k$-type of the good, myopia $\mu_{j k}^{s}$-to the monetary value of one unit of regulation stringency, variable costs of production $c_{i}$-to the actual production expenditures, and eco- 
logical footprints $\varphi_{i}$-to the expenditures required to eliminate the negative environmental impact of the production process. This data can be obtained through corresponding behavioural analysis experiments and consumer surveys.

To illustrate the algorithms, consider an example of a onelevel information provision programme $(K=1)$, which corresponds to the simplest case when the government is labelling a bunch of technologies with a single label, say "clean". The societal cost $\Phi$ is computed with amplification parameter $\gamma=0.9$.

There are three consumers in the market referred as Red, Blue, and Green. Their utilities are summarised in the Table 3. Consumer Red is eco-indifferent, while Blue and Green are ecobiased. At the same time, Green is relatively less myopic about the stringency of the information provision policy. Meanwhile, consumers have the same perception towards different stringency levels of the programme. This example represents a type of a market where consumers in general are rather sceptical about environmentally-friendly goods that implies higher budgets allocated by Red to both dirty and clean varieties.

Table 3. Example of Consumer Preferences

\begin{tabular}{lll}
\hline Consumers & Type 0 & Type 1 "Clean” \\
\hline Red & $\omega_{r, 0}=10-p_{0}$ & $\omega_{r, 1}=10-p_{l}$ \\
Blue & $\omega_{r, 0}=8-2 p_{0}$ & $\omega_{b, l}=8-p_{l}+s$ \\
Green & $\omega_{r, 0}=4-2 p_{0}$ & $\omega_{g, l}=8-p_{l}+2 s$ \\
\hline
\end{tabular}

At the current technological state, three modes of production are available. Each of the technologies is determined by a set of variable production costs and ecological footprint $\{c, \varphi\}:\{1$, $7\},\{3,5.3\},\{6,2\}$. The government makes a decision upon the design of the information provision programme choosing one of the two sets of delimiters (measured in monetary units) and stringency parameter such that $\{D, s\} \in\{\{7,0.5\},\{5.3,1\}\}$. Each set corresponds to a price space; see Figure 2.

Following the algorithms developed in Sections $4.2 \sim 4.5$, two cases are explored (Table 4). First, when the government accounts for consumer myopia, and the policy stringency influences consumer preferences. Second, when stringency does not matter and consumers are homogenous in their perception of the regulation design.

In the first case when consumer heterogeneity in eco-policy perception does matter, in Scenario $C$ the government designs a relatively more stringent information provision programme that forces Blue to leave the market. As a result, only one technology related to type "clean" (1) remains in the market. In Scenario $\mathrm{CI}$, the government is forced to degrade the quality of the programme in order to reach maximum possible social welfare when industry association aims at maximising aggregate industry profit. Therefore, all consumers remain in the market purchasing both types of the good, and hence, aggregate social cost $\Phi$ is higher than in the benchmark scenario.

The outcomes of the Scenarios $L$ and $L I$ coincide. If the government designs a voluntary information provision programme, the producers tend to avoid labelling and choose for the least environmentally efficient technology. This is due to the possibility to receive higher profits.

The developed example represents some counterintu-itive results when eco-certification dominates eco-labelling as a more desirable social programme despite a "command-andcontrol" nature of a mandatory approach. This result is expected to hold under the assumption of a high share of consumers who are ignorant to ecological threats and to implementation of the corresponding information provision programmes.

The second case shows that, without accounting for consumer perception of the information provision programme, the model delivers lower social welfare and industry profit, higher aggregate social cost $\Phi$, and less stringent optimal composition of the delimiters under Scenarios $C$ and $C I$ in comparison to the benchmark. Moreover, under Scenario $C$, only one, the least environmentally concerned consumer, remains in the market while the other two stop buying the good. The outcomes under the voluntary Scenarios $L$ and $L I$ are the same across the cases.

\section{Discussions and Conclusions}

Information provision programme can be considered as potentially efficient due to its ability to involve all economic agents-government, consumers, and producers-to the environmental protection activities. At the same time, this regulatory instrument is complex and requires a comprehensive economic analysis, mathematical modelling and computational methods. To the best of our knowledge, the information provision programmes remain rather under-investigated despite their growing importance. The current research is based on the multi-level optimisation building clear-cut algorithms for design of an optimal environmental policy based on information provision instruments. The chosen method is very generic and flexible. It allows addressing the problem in a variety of sophisticated settings, e.g., for multi-tier labelling/certification information provision programmes, for multidimensional heterogeneity of consumer ecopreferences, for a broad variety of utility and social welfare functions. These settings anticipate the complexity of consumer decision that influences the applicability of welfare and ecological outcomes of regulation.

Particularly, the research investigates four scenarios, where the assumptions are consistently relaxed accounting for possible social deviations from the benchmark case. The analysis starts from the basic scenario when all the decisions are unilaterally made by the government, and producers are not allowed to ignore the regulation. Then, the industry association that aims at maximising industry benefits rather than social welfare is introduced. At the final stage producers are allowed to make the choice whether they join the programme or not.

The current approach to policy design can be also seen as an instrument mix of two traditional regulatory tools: a consumption unit tax and an environmental unit subsidy (OECD, 2007). Implementation of such tools within the current framework heavily depends not only on the decisions made by the government and the industry association, but also on the consumer purchasing behaviour.

This research equips policy makers with clear and simple 
Table 4. Example of Policy Outcomes

\begin{tabular}{|c|c|c|c|c|c|c|}
\hline & \multicolumn{2}{|c|}{ Scenario $C$} & \multicolumn{2}{|c|}{ Scenario CI } & \multicolumn{2}{|c|}{ Scenarios $L, L I$} \\
\hline & $1 \mathrm{H}$ & $2 \mathrm{H}$ & $1 \mathrm{H}$ & $2 \mathrm{H}$ & $1 \mathrm{H}$ & $2 \mathrm{H}$ \\
\hline Social welfare* & 2.51 & 4.52 & 1.73 & 3.14 & 3.24 & 3.24 \\
\hline Industry profit ${ }^{*}$ & 7 & 8 & 13 & 14 & 9 & 9 \\
\hline Delimiter for type $1^{*}$ & 7 & 5.3 & 7 & 7 & 5.3 & 5.3 \\
\hline Stringency ${ }^{\&}$ & - & 1 & - & 0.5 & - & 1 \\
\hline Aggregate emissions ${ }^{*}$ & 5.3 & 4 & 18 & 18 & 7 & 7 \\
\hline \multicolumn{7}{|l|}{ Type 0 (no label) } \\
\hline price* & - & - & 4 & 4 & 10 & 10 \\
\hline quantity $^{\#}$ & - & - & 1 & 1 & 1 & 1 \\
\hline variable costs ${ }^{*}$ & - & - & 1 & 1 & 1 & 1 \\
\hline footprint ${ }^{*}$ & - & - & 7 & 7 & 7 & 7 \\
\hline firm's profit ${ }^{*}$ & - & - & 3 & 3 & 9 & 9 \\
\hline \multicolumn{7}{|l|}{ Type 1 (clean) } \\
\hline price $^{*}$ & 10 & 10 & 8 & 8.5 & - & - \\
\hline quantity & 1 & 2 & 2 & 2 & - & - \\
\hline variable costs ${ }^{*}$ & 3 & 6 & 3 & 3 & - & - \\
\hline footprint ${ }^{*}$ & 5.3 & 2 & 5.3 & 5.3 & - & - \\
\hline firm's profit ${ }^{*}$ & 7 & 8 & 5 & 5.5 & - & - \\
\hline \multicolumn{7}{|l|}{ Consumers } \\
\hline Red & $\mathrm{t} 1$ & $\mathrm{t} 1$ & to & $\mathrm{t} 0$ & to & to \\
\hline Blue & - & - & $\mathrm{t} 1$ & $\mathrm{t} 1$ & - & - \\
\hline Green & - & $\mathrm{t} 1$ & $\mathrm{t} 1$ & $\mathrm{t} 1$ & - & - \\
\hline
\end{tabular}

Notes: (a) $1 \mathrm{H}$ corresponds to the case when consumers are allowed to allocate different budgets to the goods of different types but their purchasing choices do not account for the stringency of the regulation (s).

(b) $2 \mathrm{H}$ corresponds to the case when consumers are allowed to allocate different budgets to the goods of different types and their purchasing choices account for the stringency of the regulation (s).

(c) t0 corresponds to the good of type 0 .

(d) $\mathrm{t} 1$ corresponds to the good of type 1 .

(e) Variables indicated by * are measured in monetary units.

(f) Variables indicated by \# are measured in production units.

(g) Variables indicated by \& are multiplying coefficients (see equation (5)).

algorithms accounting for a set of crucially important characteristics of the market to design the optimal regulatory policy. Meanwhile, several important limitations should be mentioned. First, the chosen approach is predominantly customer-centered. It neglects a possible pro-active behaviour of producers whose role within the model is reduced to the decision on technological choice and eco-labelling introduction. At the same time, the activity of producers can drastically influence the outcomes of environmental policy (see, for example, Fischer and Lyon, 2017). Thus, the current framework could be enriched by allowing for firms heterogeneity and respective heterogeneous decisions. Second, the research introduces two new parameters, namely, policy stringency and consumer myopia, to proxy the appreciation of environmental policy by consumers. These parameters are not able to capture the whole range of factors that can possibly influence the purchasing decision, and therefore, the policy outcomes. Third, information provision programme is assumed to be costless within the model due to firms' market power neglecting. Nevertheless, in case of firms' heterogeneity, costly policy can incur possible additional insights to the model.

All-in-all, despite some underpinning assumptions and limitations, the current approach contributes to the environmental policy analysis shedding the light on the optimal design of the information provision programmes and their social and environmental outcomes. Moreover, the proposed approach is extremly intuitive and simple, which it perfect for practical implementations of actual environmental policies. Furthermore, for a small number of labels/certificates, the underlying algorithms are computationally efficient even for large markets represented by many producers and numerous consumers. This research provides a useful and simple instrument to be implemented by policy makers when choosing the best information provision policy design.

Acknowledgments. We thank the Doctoral Programme of AixMarseille School of Economics for financial support. We are also deeply grateful to Sergey Kokovin, Antonella Nocco, Pierre Picard, Federico Trionfetti, and Thomas Ziesemer, and two anonymous referees for their valuable comments and insights.

\section{References}

Albrizio, S., Botta E., Koźluk, T., and Zipperer, V. (2014). Do Environmental Policies Matter for Productivity Growth?: Insights from New Cross-Country Measures of Environmental Policies. OECD Economics Department Working Papers, No. 1176, OECD Publishing, Paris. https://doi.org/10.1787/5jxrjncjrcxp-en 
Bernoulli, D. (1738). Specimen Theoriae Novae de Mensura Sortis (translated from Latin into English by L. Sommer in 1954). Commentarii Academiae Scientiarium Imperalis Petropolitanae V, 175-192.

Bjørner, T.B., Hansen, L.G., and Russell, C.S. (2004). Environmental labeling and consumers' choice-an empirical analysis of the effect of the Nordic Swan. J. Environ. Econ. Manage., 47, 411-434. https: //doi.org/1 0.1016/j.jeem.2003.06.002

Carlsson, F., García, J.H., and Löfgren, Å. (2010). Conformity and the demand for environmental goods. Environ. Resour. Econ., 47, 407421. https://doi.org/10.1007/s10640-010-9385-2

Council of the European Communities (1992). Council Directive 92/75/EEC of 22 September 1992, http://eurlex.europa.eu/legalcontent/EN/TXT/?uri=CE LEX Council of the European Communities.

Cowan, N. (2000). The magical number 4 in short-term memory: A reconsideration of mental storage capacity. Behav. Brain. Sci., 24 87-185. https://doi.org/10.1017/S0140525X01003922

Darby, M.R. and Karni, E. (1973). Free competition and the optimal amount of fraud. J. Law Econ., 16 (1), 67-88. https://doi.org/10.10 $86 / 466756$

Fischer, C. and Lyon, T. P. (2017). A theory of multi-tier ecolabels. Unpublished. Retrieved from https://www.aeaweb.org/conference /2014/retrieve.php?pdfid=89308.07.2017

Goulder, L. H. and Parry, I. W. (2008). Instrument choice in environmental policy. Rev. Environ. Econo. Policy, 2(2), 152-174. https:// doi.org/10.1093/reep/ren005

Gruère, G. (2013). A characterisation of environmental labelling and information schemes. OECD Environment Working Papers, No.62. https://doi.org/10.1787/5k3z11hpdgq2-en

Ingwersen, W. W. and Stevenson, M. J. (2012). Can we compare the environmental performance of this product to that one? An update on the development of product category rules and future challenges toward alignment. J. Cleaner Prod., 102-108. https://doi.org/10.10 16/j.jclepro.2011.10.040

Lu, J., Han, J., Hu, Y. and Zhang, G. (2016). Multilevel decisionmaking: A survey. Inf. Sci., 346-347, 463-487. https://doi.org/10.1 016/j.ins.2016.01.084

Miller, G. A. (1956). The magical number seven, plus or minus two: some limits on our capacity for processing information. Psychol. Rev., 63(2), 81-97. https://doi.org/10.1037/h0043158.

Minkov, N., Schneider, L. Lehmann, A. and Finkbeiner, M. (2015). Type III environmental declaration programmes and harmonization of product category rules: status quo and practical challenges. $J$. Cleaner Prod., 94, 235-246. https://doi.org/10.1016/j.jclepro.20 15.02 .012

OECD (2007). Instrument mixes for environmental policy. Technical report, OECD. https://doi.org/10.1787/9789264018419-en

Stackelberg, H. (1952). The Theory of Market Economy. Oxford University Press, Oxford.

Tegos, G.K. and Onkov, K.Z. (2009). Algorithm for Categorizing Fish Species at Risk. J. Environ. Inf., 14(2), 83-88. https://doi.org/10.38 08/jei.200900156

Tietenberg, T. (1998). Disclosure strategies for pollution control. Environ. Resour. Econ., 11(3-4), 587-602. https://doi.org/10.1023/ A: 1008291411492

Vicente, L. N. and Calamai, P. H. (1994). Bilevel and multilevel programming: A bibliography review. J. Global Optimiz., 5(3), 291-306.https://doi.org/10.1007/BF01096458

Yeomans, J. S. (2008). Applications of Simulation-Optimization Methods in Environmental Policy Planning Under Uncertainty. $J$. Environ. Inf., 12(2), 174-186. https://doi.org/10.3808/jei.200800135 